\title{
SPECIAL FEATURES OF THE FORMATION OF THE MICROSTRUCTURE OF THE 09G2S STEEL UNDER CONDITIONS OF COLD AND WARM EQUAL-CHANNEL ANGULAR PRESSING
}

\author{
A. V. Makarov ${ }^{1,2}$, S. P. Yakovleva ${ }^{3}$, E. G. Volkova ${ }^{1}$, S. N. Makharova ${ }^{3}$, P. G. Mordovskoy ${ }^{3}$ \\ ${ }^{I}$ M.N. Miheev Institute of Metal Physics, Ural Branch of the Russian Academy of Sciences, \\ 18 S. Kovalevskoy St., Ekaterinburg, Russian Federation \\ ${ }^{2}$ Institute of Engineering Science, Ural Branch of the Russian Academy of Sciences, \\ 34 Komsomolskaya St., Ekaterinburg, Russian Federation \\ ${ }^{3}$ V.P. Larionov Institute of the Physical-Technical Problems of the North, SO RAS, \\ 1 Oktyabrskaya St., Yakutsk, Russian Federation
}

*Corresponding author. E-mail:volkova@imp.uran.ru; address for correspondence: 18, ul. S. Kovalevskoy, Ekaterinburg, Russian Federation. Tel.: +7 (343) 3783527

Translucent electron microscopy is used to make a comparative analysis of the microstructure of the 09G2S steel in the initial state, after equal-channel angular pressing (ECAP) at $20^{\circ} \mathrm{C}$ and after warm ECAP at $450{ }^{\circ} \mathrm{C}$. The effect of ECAP at $20{ }^{\circ} \mathrm{C}$ leads to the formation of a mixed (subgranular and cellular) ferrite structure and the destruction of pearlite colonies. There occur the crushing and spheroidization of cementite particles. Warm ECAP deformation at $450{ }^{\circ} \mathrm{C}$ contributes to the formation of a polygonized structure with submicron scale elements in ferrite. In the main, the pearlite colonies undergo insignificant changes, and there are individual sections with destroyed pearlite colonies and severe dispersion of cementite. The mechanical properties of the steel in three examined structural states are presented.

Keywords: low-carbon steel, microstructure, equal-channel angular pressing, electron microscopy, mechanical properties.

DOI: $10.17804 / 2410-9908.2016 .6 .039-047$

\section{References}

1. Valiev R.Z., Aleksandrov I.V. Obyomnye nanostrukturnye metallicheskie materialy [Bulk Nanostructured Metal Materials]. Moscow, Akademkniga Publ., 2007, 398 p. ISBN 978-5-94628-217-8. (In Russian).

2. Gleiter H. Nanostructured materials: basic concepts and microstructure. Acta Materialia, 2000, vol. 48, iss. 1, pp. 1-29. DOI: 10.1016/S1359-6454(99)00285-2.

3. Andrievskii R.A., Glezer A.M. Strength of nanostructures. Physics-Uspekhi, 2009, vol. 52, no. 4, pp. 315-334. DOI: 10.3367/UFNe.0179.200904a.0337.

4. Makarov A.V., Savrai R.A., Malygina I.Yu., Pozdeeva N.A. Effect of strengthening friction treatment on the mechanical properties and specific features of the deformation of low-carbon steel under static and cyclic loading. Fizika $i$ khimiya obrabotki materialov, 2009, no. 1. pp. 92-102. (In Russian).

5. Makarov A.V., Savrai R.A., Gorkunov E.S., Yurovskikh A.S., Malygina I.Yu., Davydova N.A. Structure, mechanical characteristics, and deformation and fractures of quenched structural steel under static and cyclic loading after combined strain-heat nanostructuring treatment. Physical Mesomechanics, 2015, vol. 18, no. 1, pp. 43-57. DOI: 10.1134/S1029959915010063.

6. Noskova N.I., Mulyukov R.R. Submikrokristallicheskie i nanokristallicheskie metally $i$ splavy [Submicrocrystalline and Nanocrystalline Metals and Alloys]. Ekaterinburg, UrO RAN Publ., 2003, 279 p. (In Russian).

7. $\quad$ Rudskoi A.I. Kodzhaspirov G.E. Ultramelkozernistye metallicheskie materialy [Ultra-Finely Dispersed Metal Materials]. SPb., Izd-vo Politekhn. un-ta Publ., 2015, 360 p. (In Russian). 
8. Degtyarev M.V., Chashchukhina T.I., Voronova L.M. Grain Growth in Dynamically Recrystallized Copper During Annealing above and below the Temperature of Thermally Activated Nucleation. Diagnostics, Resource and Mechanics of materials and structures, 2016, iss. 5, pp. 15-29. DOI: 10.17804/2410-9908.2016.5.015-029. Available at: http://dreamjournal.org/DREAM_Issue_5_2016_Degtyarev_M.V._et_al._015_029.pdf.

9. Makarov A.V., Pozdeeva N.A., Savrai R.A., Yurovskikh A.S., Malygina I.Yu. Improvement of wear resistance of hardened structural steel by nanostructuring frictional treatment. Journal of Friction and Wear, 2012, vol. 33, no. 6, pp. 433-442. DOI: 10.3103/S10683666120600.

10. Makarov A.V., Davydova N.A., Malygina I.Y., Lyzhin V.V., Korshunov L. G. Improving the thermal stability and heat wear resistance of carburized chromium-nickel steel by nanostructuring frictional treatment. Diagnostics, Resource and Mechanics of materials and structures, 2016, iss. 5, pp. 49-66. DOI: 10.17804/2410-9908.2016.5.049-066. Available at: http://dreamjournal.org/DREAM_Issue_5_2016_Makarov_A.V._et_al._049_066.pdf.

11. Yakovleva S.P., Makharova S.N., Mordovskoi P.G., Borisova M.Z. Effect of the conditions of bulk nanostructuring by megaplastic deformation on the properties of structural steel. Perspektivnye materialy, 2011, no. 13, pp. 961-967. (In Russian).

12. Yakovleva S.P., Makharova S.N., Mordovskoi P.G. Effect of combined megaplastic deformation on the structure and properties of steel 09G2S. Obrabotka metallov, 2016, no. 1 (70), pp. 52-56. (In Russian).

13. Astafurova E.G., Zakharova G.G., Naydenkin E.V., Dobatkin S.V., Raab G.I. Influence of equal-channel angular pressing on the structure and mechanical properties of low-carbon steel 10G2FT. The Physics of Metals and Metallography, 2010, vol. 110, no. 3, pp. 260-268. DOI: $10.1134 /$ S0031918X10090097.

14. Sestri Sh.M.L., Dobatkin S.V., Sidorova S.V. Formation of a submicrocrystalline structure in steel 10G2FT under cold equal-channel angular pressing followed by heating. Metally, 2004, no. 2, pp. 28-35. (In Russian).

15. Dobatkin S.V., Odessky P.D., Pippan R., Raab G.I., Krasilnikov N.A., Arsenkin A.M. Warm and hot equal-channel angular pressing of low-carbon steels. Metally, 2004, no. 1, pp. 110-119. (In Russian).

16. Tereshchenko N.A., Yakovleva I.L., Chukin M.V., Efimova Y.Y. Development of the rotational mode of plastic deformation upon drawing of pearlitic steels of various alloying systems. The Physics of Metals and Metallography, 2015, vol. 116, no. 3, pp. 274-284. DOI: 10.1134/S0031918X15030151.

17. Gavrilyuk V.G. Raspredelenie ugleroda v stali [Distribution of Carbon in Steel]. Kiev, Naukova Dumka Publ., 1987, 208 p. (In Russian).

18. Dobatkin S.V., Kaputkina L.M. Maps of structural states for the optimization of hot-working regimes of steels. The Physics of Metals and Metallography, 2001, vol. 91, no. 1, pp. 75-84.

19. Zakharova G.G., Astafurova E.G., Tukeeva M.S., Naydenkin E.V., Raab G.I., Dobatkin S.V. Mechanical properties of ferritic-pearlitic and martensitic steel 10G2FT after equalchannel angular pressing and high-temperature annealings. Izvestiya vysshykh uchebnykh zavedeniy. Fizika, 2011, no. 4, pp. 23-28. (In Russian). 
Подана в журнал: 12.12 .2016

УДК 669.15:621.777:620.186

DOI: $10.17804 / 2410-9908.2016 .6 .039-047$

\title{
ОСОБЕННОСТИ ФОРМИРОВАНИЯ МИКРОСТРУКТУРЫ СТАЛИ 09Г2С В УСЛОВИЯХ ХОЛОДНОГО И ТЕПЛОГО РАВНОКАНАЛЬНОГО УГЛОВОГО ПРЕССОВАНИЯ
}

\author{
А. В. Макаров ${ }^{1,2}$, С. П. Яковлева ${ }^{3}$, Е. Г. Волкова ${ }^{1 *}$, С. Н. Махарова ${ }^{3}$, П. Г. Мордовской ${ }^{3}$ \\ ${ }^{1}$ Федеральное государственное бюджетное учреждение науки Институт физики металлов \\ имени М.Н. Михеева Уральского отделения Российской академии наук, \\ ул. С. Ковалевской, 18, Екатеринбург, Россия \\ ${ }^{2}$ Федеральное государственное бюджетное учреждение науки Институт машиноведения \\ Уральского отделения Российской академии наук, ул. Комсомольская, 34, Екатеринбург, Россия \\ ${ }^{3}$ Институт физико-технических проблем Севера им. В.П. Ларионова СО РАН, ул. Октябрьская, 1, \\ Якутск, Россия \\ *Ответственный автор. Электронная почта: volkova@imp.uran.ru, адрес для переписки: 620990, \\ ул. С. Ковалевской, 18, Екатеринбург, Россия. Телефон: +7 (343) 374-40-54; Факс: +7 (343) 374-52-44.
}

В настоящей работе с использованием просвечивающей электронной микроскопии проведен сравнительный анализ микроструктуры стали 09Г2С в исходном состоянии после холодного равноканального углового прессования (РКУП) при $20{ }^{\circ} \mathrm{C}$ и после теплого РКУП при $450{ }^{\circ} \mathrm{C}$. Воздействие методом РКУП при $20^{\circ} \mathrm{C}$ приводит к формированию смешанной (субзеренной и ячеистой) структуры феррита и разрушению перлитных колоний. Происходит измельчение и сфероидизация цементитных частиц. Теплая деформация РКУП при $450{ }^{\circ} \mathrm{C}$ способствует формированию полигонизированной структуры с элементами субмикронного масштаба в феррите. Перлитные колонии в основном претерпевают незначительные изменения, наблюдаются также и отдельные участки с разрушенными колониями перлита и сильным диспергированием цементита. Представлены механические свойства стали в трех рассмотренных структурных состояниях.

Ключевые слова: низколегированная сталь, микроструктура, равноканальное угловое прессование, электронная микроскопия, механические свойства.

\section{1. Введение}

Низколегированные и простые углеродистые конструкционные стали широко применяются в различных областях производства. Они не требуют легирования такими элементами как хром, ванадий или алюминий, что существенно удорожает производство стали. Но в то же время их прочностные характеристики значительно уступают свойствам высокоуглеродистых и высоколегированных сталей. Одним из путей повышения прочности и пластичности углеродистых и низколегированных конструкционных сталей является применение больших пластических деформаций, позволяющих создавать в материалах наноструктурное и субмикрокристаллическое состояния [1-5]. В настоящее время существует множество способов для реализации больших пластических деформаций в объеме [6-8] и на поверхности $[9,10]$ металлических материалов. Для повышения прочностных характеристик низколегированных сталей широко применяется такая обработка как равноканальное угловое прессование (РКУП) [11-14]. Указанный метод позволяет создать в низколегированных сталях микрокристаллическое или субмикрокристаллическое состояние с высокими прочностными характеристиками. Формирующееся в низкоуглеродистых конструкционных сталях структурное состояние в сильной степени зависит от температуры, при которой реализуется РКУП [15]. 
Цель настоящей работы - проведение с использованием метода просвечивающей электронной микроскопии сравнительного анализа структуры феррито-перлитной низколегированной стали 09Г2С после РКУП при температурах прессования $20{ }^{\circ} \mathrm{C}$ и $450{ }^{\circ} \mathrm{C}$.

\section{2. Материал и методика эксперимента}

Исследования проводили на низколегированной конструкционной стали 09Г2С:

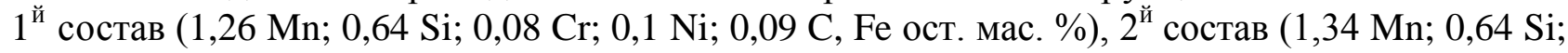
0,14 Cr; 0,09 Ni; 0,09 C, Fe ост. мас. \%). Форма заготовок цилиндрическая, диаметр 20 мм, длина 100 мм. РКУП проведено по маршруту «Вс» (поворот на 90 после каждого цикла прессования) на установке с углом пересечения каналов $120^{\circ}$, температуры прессования $20{ }^{\circ} \mathrm{C}\left(1^{\breve{~}}\right.$ состав) или $450{ }^{\circ} \mathrm{C}\left(2^{\breve{~ и ̆ ~}}\right.$ состав), число циклов прессования 2 и 4 соответственно. Химический анализ стали определен на спектрометре «FOUNDRY MASTER UVR WAS AG». Испытания для определения механических свойств проводились на универсальной электромеханической испытательной машине «ZWICK/ROELL Z600» при скорости деформирования 1 мм/мин и величине предельной нагрузки 1 т. Исследование тонкой структуры осуществляли методом электронной просвечивающей микроскопии (ПЭМ) на микроскопе JEOL JEM200СX с применением механического и электролитического утонения заготовок (фольг).

\section{3. Экспериментальные результаты и обсуждение}

Исследование методом просвечивающей микроскопии исходной структуры стали показало, что основную часть структуры занимает ферритная составляющая. Ферритные зерна достаточно крупные, внутри зерен присутствует небольшое количество дислокаций рис. $1 a$, плотность дислокаций небольшая. Общий вид перлитных колоний показан на рис. 16 . Средний размер перлитных колоний 2-4 мкм. Межпластинчатое расстояние внутри перлитной колонии $0,10-0,25$ мкм. Колонии не идеальны, но часть колоний имеет правильное регулярное строение. Часто наблюдается обрыв цементитных пластин, имеются участки с изгибом пластин. Межфазная граница феррит-цементит не всегда плоская, изредка встречаются ступени, скопления дислокаций отсутствуют. Плотность дислокаций в феррите перлитной колонии низкая (рис. 1 б). Особенности дифракционного контраста на электронно-микро-скопических снимках свидетельствуют о небольшой разориентации структурных элементов внутри перлитных колоний.

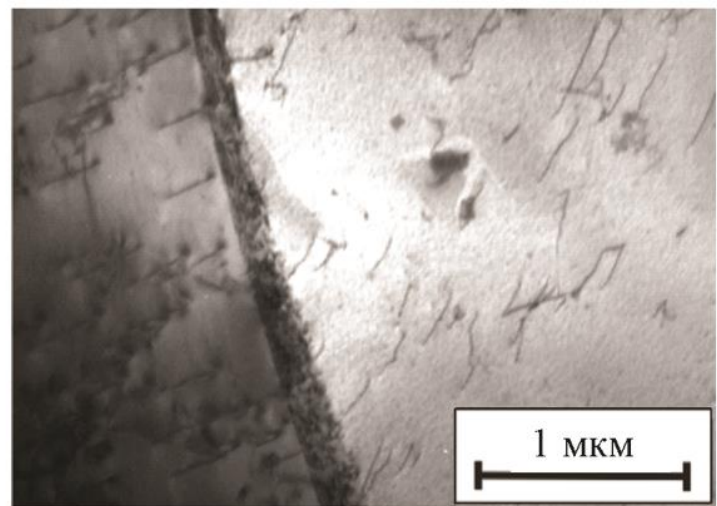

$a$

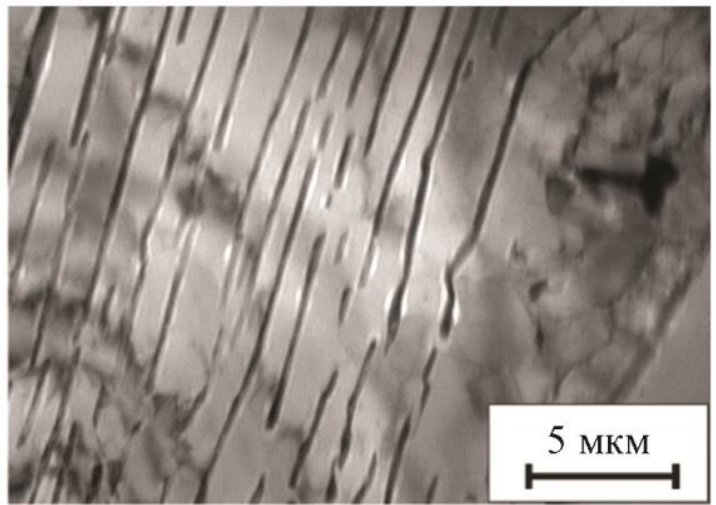

$\sigma$

Рис. 1. Электронно-микроскопические изображения структуры стали 09Г2С в исходном состоянии: $a$ - ферритные зерна; $\sigma$ - перлитная колония; светлопольные изображения

На рис. 2 а показана структура, характерная для образца после РКУП при температуре $20{ }^{\circ} \mathrm{C}$. Размер зерна сильно изменился, произошло формирование преимущественно субзеренной и ячеистой структуры, отдельные небольшие участки можно даже характеризовать

Makarov A.V. et al. / Special features of the formation of the microstructure of the 09G2S steel under 
как субмикрокристаллические с большеугловой разориентировкой зерен. Наблюдаются как участки с вытянутой структурой с преимущественно малоугловыми границами, так и равноосные структурные элементы с большеугловыми границами. Плотность дислокаций внутри зерен увеличилась, границы стали размытыми. На снимках присутствуют зерна размером 720-130 нм, средний размер зерна для подобных участков 320 нм, картины микродифракции могут содержать несколько осей зон от разных зерен. Небольшое радиальное размытие всех рефлексов на рис. 2 б свидетельствует о постепенном изменении ориентировок между отдельными структурными элементами.

В структуре стали после РКУП при комнатной температуре отсутствуют перлитные колонии, наблюдавшиеся в исходной структуре. Присутствуют участки с вытянутыми зернами (рис. 2 в), размер зерна на таких участках составляет 380-50 нм, средний размер зерна 140 нм. Картина микродифракции становится кольцевой (рис. 2 2), что может свидетельствовать об измельчении зерна. Внутри первого кольца видны отдельные рефлексы цементита (показано стрелкой на рис. 2 2). На рис. 2 д наблюдаются цементитные частицы размером 80-7 нм, средний размер цементитных частиц $~ 30$ нм. Произошло разбиение колоний и «разнос» цементита по ферриту. Встречаются как отдельные фрагменты цементитных пластин, так и мелкодисперсные частицы цементита.

Таким образом, холодное РКУП привело к образованию смешанной (субзеренной и ячеистой) структуры $\alpha$-фазы. Произошло также перераспределение и разрушение цементита перлитных колоний. Вместо тонкопластинчатых колоний возникают мелкодисперсные сферические частицы цементита.

В таблице приведены прочностные характеристики стали 09Г2С. Видно, что РКУП при $20{ }^{\circ} \mathrm{C}$ приводит к трехкратному увеличению пределов текучести и прочности, однако резко уменьшает пластичность стали. Такие высокие прочностные свойства связаны как с существенным уменьшением среднего размера структурных элементов, так и с созданием высоких внутренних напряжений в процессе РКУП [16]. Происходит практически полное разрушение перлитных колоний и сфероидизация пластин цементита, подобное явление при холодной деформации с большой степенью наблюдалось в разных работах, например в [14]. Деформация и сфероидизация пластин цементита в перлите сопровождается растворением цементита и диффузией углерода в ферритную матрицу. Считается, что эти процессы могут снижать пластичность стали [17].

Механические характеристики стали 09Г2С в различных состояниях

\begin{tabular}{|c|c|c|c|}
\hline Состояние материала & $\sigma_{0,2}$, МПа & $\sigma_{\mathrm{B}}, \mathrm{M \Pi а}$ & $\delta, \%$ \\
\hline Исходное & 350 & 480 & 32 \\
\hline $\begin{array}{c}\text { РКУП при } 20^{\circ} \mathrm{C}, \\
2 \text { цикла }\end{array}$ & 930 & 1300 & 4,0 \\
\hline $\begin{array}{c}\text { РКУП при } 450^{\circ} \mathrm{C}, \\
4 \text { цикла }\end{array}$ & 1005 & 1010 & 4,9 \\
\hline
\end{tabular}

Makarov A.V. et al. / Special features of the formation of the microstructure of the 09G2S steel under 


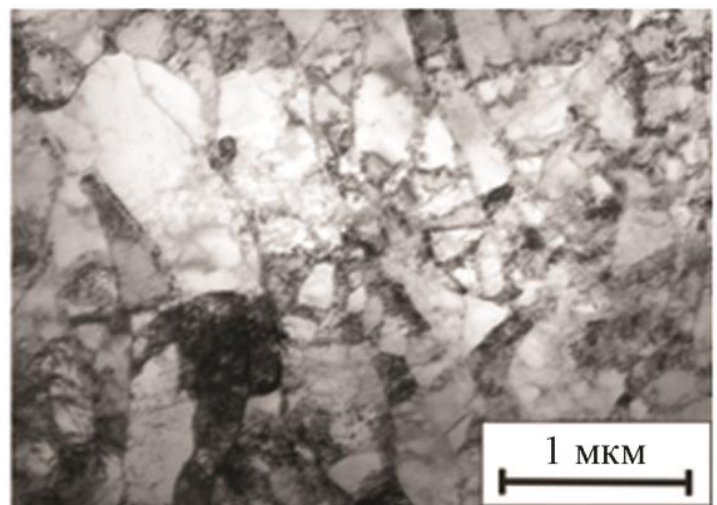

$a$

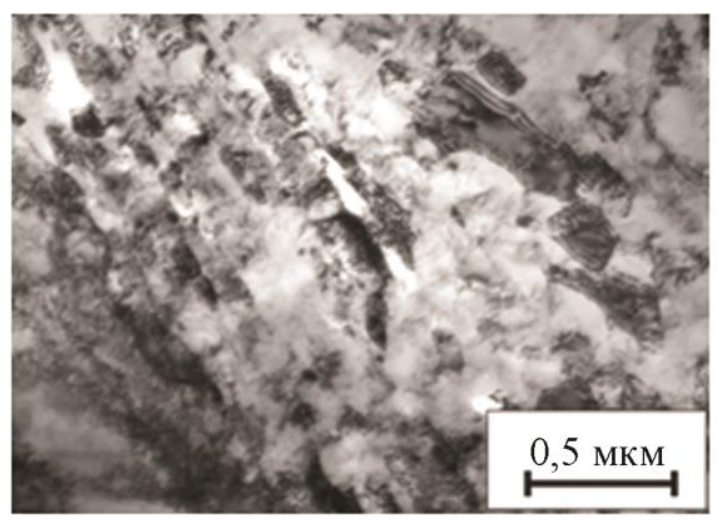

B

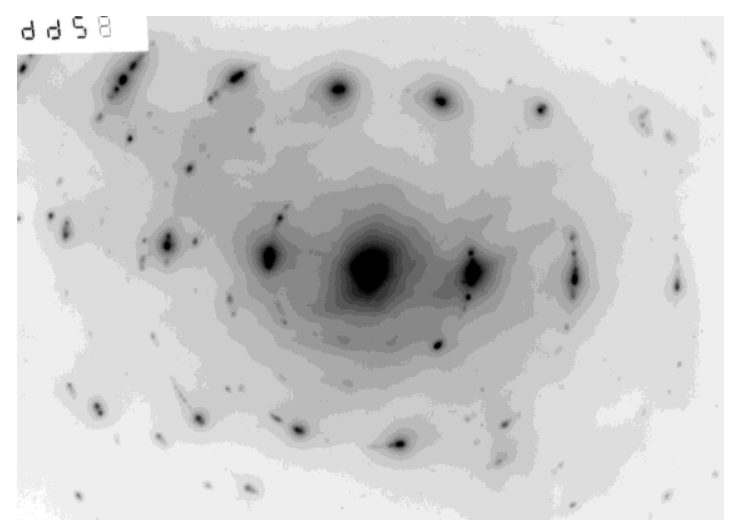

$\sigma$

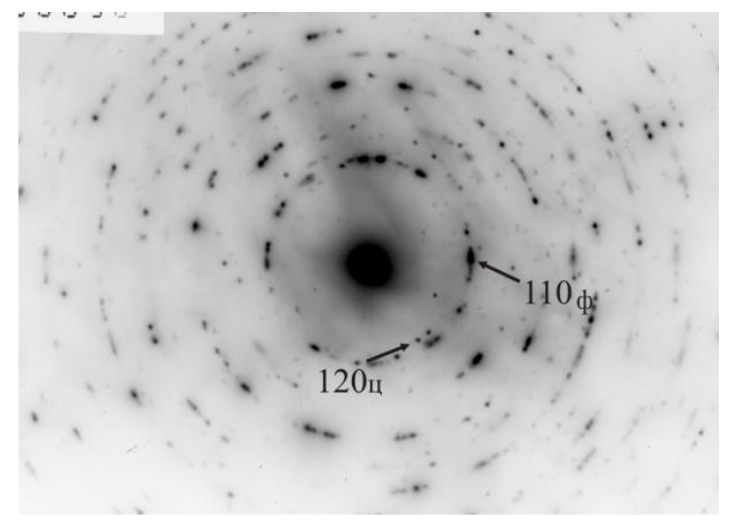

2

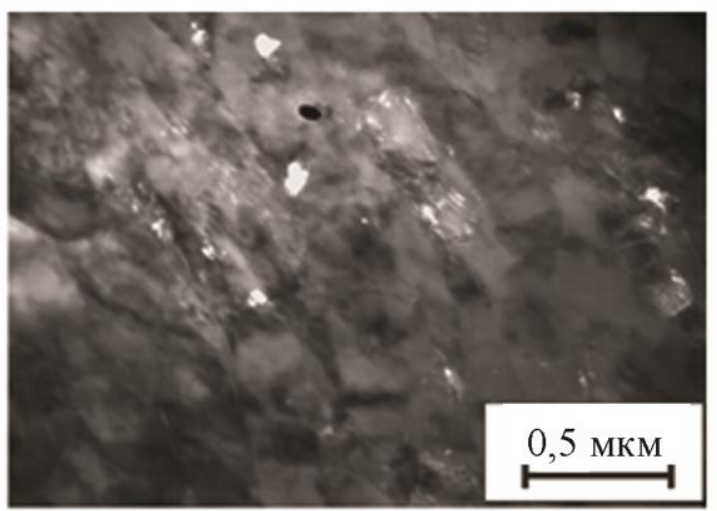

$\partial$

Рис. 2. Электронно-микроскопические изображения структуры стали 09Г2С после РКУП при температуре $20^{\circ} \mathrm{C}, 2$ цикла: $a$ - ферритные зерна, светлопольное изображение; $\sigma$ - картина микродифракции; в - остатки перлитной колонии, светлопольное изображение; 2 - картина микродифракции; $\partial$ - темнопольное изображение в рефлексе цементита

На рис. 3 представлена структура стали после РКУП (4 прохода) при температуре $450{ }^{\circ} \mathrm{C}$. Видно (рис. 3 a, б), что в результате теплого РКУП формируется динамически полигонизованная преимущественно равноосная структура феррита, подобная структура была получена в работах $[15,18]$ на стадии установившейся деформации. Размер зерна $\alpha$-фазы уменьшился по сравнению с размером зерна исходного образца (рис. 1 ). Внутри отдельных зерен микронного масштаба формируются субзерна с малоугловыми разориентировками. Встречаются также отдельные области с субмикрокристаллической структурой. Внутри зерен повысилась плотность дислокаций. Дислокации выстраиваются в сетки и стенки, грани-

Makarov A.V. et al. / Special features of the formation of the microstructure of the 09G2S steel under 
цы становятся более округлыми. Таким образом, в процессе РКУП при $450{ }^{\circ} \mathrm{C}$ произошло формирование микрокристаллической структуры $\alpha$-фазы с развитой субструктурой и элементами субмикронного масштаба.

На рис. 3 в, г показана структура перлитных колоний после теплого РКУП. Рис. 3 в демонстрирует сохранившиеся колонии перлита, межпластинчатое расстояние внутри перлитной колонии осталось практически неизменным (0,1-0,3 мкм) по сравнению с межпластинчатым расстоянием перлита в исходном состоянии (рис. 1 б). После теплого РКУП пластины цементита внутри перлитных колоний расположены не параллельно (рис. 3 в). Увеличивается количество оборванных пластин. Сами пластины сильно колеблются по толщине. Межфазная граница феррит-цементит изогнутая, встречаются ступени и сколы. Увеличивается плотность дислокаций внутри ферритных прослоек. Имеются участки структуры, где произошло разрушение колоний и разнос цементита (рис. 3 г). В рефлексе цементита светятся не только крупные фрагменты, но и мелкие частицы цементита размером 20-50 нм.

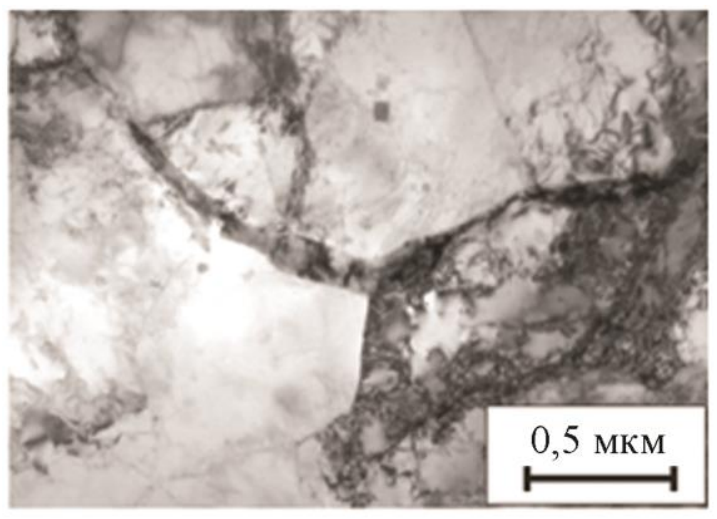

$a$

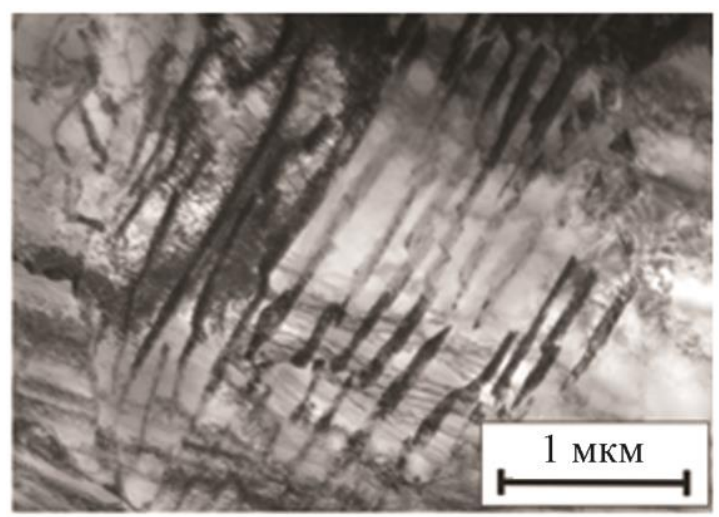

B

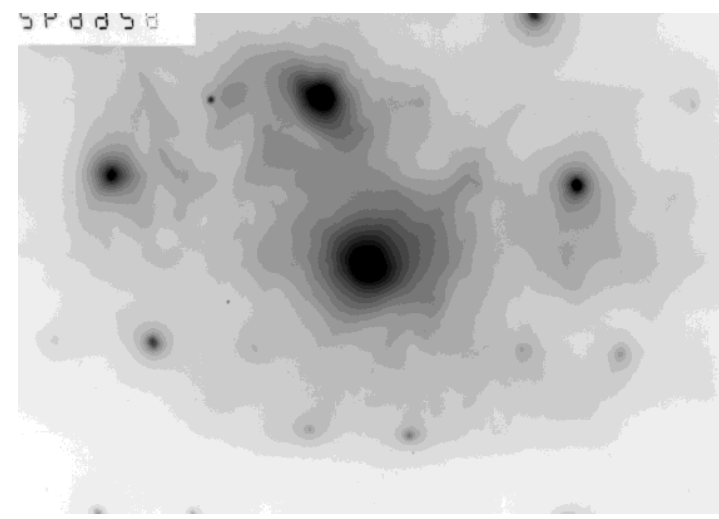

$\sigma$

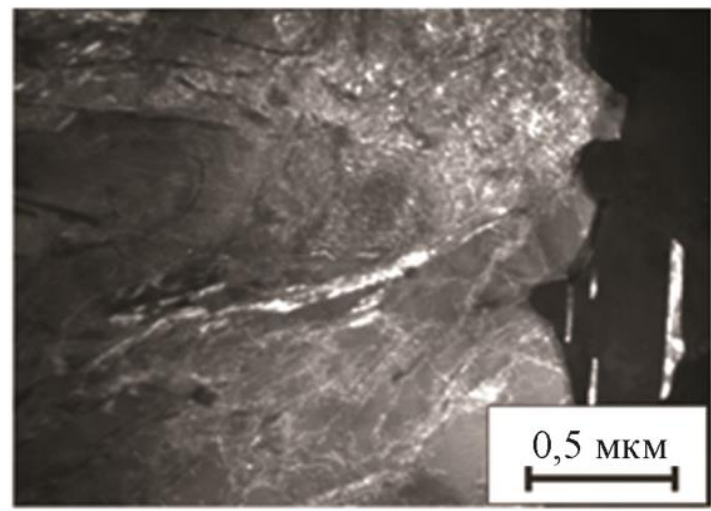

2

Рис. 3. Электронно-микроскопические изображения структуры стали 09Г2С после РКУП при температуре $450{ }^{\circ} \mathrm{C}, 4$ цикла: $a$ - ферритные зерна, светлопольное изображение; $\sigma$ - картина микродифракции; в - перлитная колония, общий вид, светлопольное изображение; 2 - темнопольное изображение разрушенной перлитной колонии в рефлексе цементита

Данные таблицы свидетельствуют о достижении высоких прочностных характеристик ( 1000 МПа) стали в результате теплого РКУП. Существенно более низкий уровень предела прочности после РКУП при $450{ }^{\circ} \mathrm{C}\left(\sigma_{0,2}=1010 \mathrm{MПа}\right)$, чем после РКУП при $20{ }^{\circ} \mathrm{C}\left(\sigma_{\mathrm{B}}=1300\right.$ МПа), можно объяснить меньшим измельчением структурных элементов (феррита, цементита перлитных колоний) при теплом РКУП, несмотря на большее количестве циклов прессования при температуре $450{ }^{\circ} \mathrm{C}$. Это может быть связано с развитием процессов возврата при более высоких температурах деформации. Например, в работе [19] РКУП стали 10Г2ФТ

Makarov A.V. et al. / Special features of the formation of the microstructure of the 09G2S steel under 
приводит к измельчению зерна в феррито-перлитном состоянии с 4200 нм до 260 нм, а последующие отжиги при 300, 400 и $500{ }^{\circ} \mathrm{C}$, когда еще нет рекристаллизации, приводят к росту зерна до 320, 380 и 410 нм соответственно, что авторы работы [19] связывают с возвратом структуры.

Из данных таблицы следует также, что теплое РКУП не обеспечило по сравнению с холодным РКУП роста пластичности (относительное удлинение $\delta=4,0-4,9 \%$ ), которая существенно уступает пластичности стали с исходной крупнокристаллической структурой $(\delta=29 \%)$.

\section{4. Заключение}

Методом просвечивающей электронной микроскопии установлено, что в стали 09Г2С с исходной феррито-перлитной структурой 2 цикла РКУП при температуре $20^{\circ} \mathrm{C}$ приводят к образованию смешанной (субзеренной и ячеистой) структуры феррита. Перлитные колонии разбиваются, вместо пластинчатой структуры цементита возникают мелкодисперсные наноразмерные частицы цементита (средний размер 30 нм), которые упрочняют ферритную составляющую деформированной структуры. Это обеспечивает значительный рост прочностных характеристик стали при испытаниях на растяжение до $\sigma_{0,2}=930 \mathrm{MПа} \mathrm{и} \sigma_{\mathrm{B}}=1300 \mathrm{MПа}$ при значительном снижении пластичности стали.

РКУП, 4 цикла, при температуре $450{ }^{\circ} \mathrm{C}$ приводит к формированию менее дисперсной динамически полигонизованной структуры феррита с зернами микронного масштаба с развитой субструктурой субмикронного масштаба. Теплая деформация сопровождается сохранением значительной доли перлитных колоний. Однако присутствуют и отдельные участки, на которых произошло разрушение перлитных колоний и сильное диспергирование цементита. Указанная эволюция структуры при теплом РКУП обусловила рост прочностных характеристик стали до $\sigma_{0,2}=1005 \mathrm{MПа,} \sigma_{\mathrm{B}}=1010 \mathrm{MПа}$, однако не обеспечила по сравнению с холодным РКУП роста пластичности.

\section{Благодарность}

Работа выполнена в рамках государственного задания по теме «Структура» № 01201463331. Электронная просвечивающая микроскопия выполнена в Центре коллективного пользования «Электронная микроскопия» УрО РАН - отделе электронной микроскопии «Испытательного центра нанотехнологий и перспективных материалов» ИФМ УpO РAH.

\section{Литература}

1. Валиев Р. 3., Александров И. В. Объемные наноструктурные металлические материалы: получение, структура и свойства. - М.: Академкнига, 2007. - 398 с.

2. Gleiter H. Nanostructured materials: basic concepts and microstructure // Acta Materialia. 2000. - Vol. 48, iss. 1. - P. 1-29. - DOI: 10.1016/S1359-6454(99)00285-2.

3. Andrievskii R. A., Glezer A. M. Strength of nanostructures // Physics-Uspekhi. - 2009. Vol. 52, no. 4. - P. 315-334. - DOI: 10.3367/UFNe.0179.200904a.0337.

4. Влияние упрочняющей фрикционной обработки на механические свойства и особенности деформирования при статическом и циклическом нагружении низкоуглеродистой стали / А. В. Макаров, Р. А. Саврай, И. Ю. Малыгина, Н. А. Поздеева // Физика и химия обработки материалов. - 2009, № 1. - С. 92-102.

5. Structure, mechanical characteristics, and deformation and fractures of quenched structural steel under static and cyclic loading after combined strain-heat nanostructuring treatment / A. V. Makarov, R. A. Savrai, E. S. Gorkunov, A. S. Yurovskikh, I. Yu. Malygina, 
N. A. Davydova // Physical Mesomechanics. - 2015. - Vol. 18, no. 1. - P. 43-57. DOI: $10.1134 / \mathrm{S} 1029959915010063$.

6. Носкова Н. И., Мулюков Р. Р. Субмикрокристаллические и нанокристаллические металлы и сплавы. - Екатеринбург: УрО РАН, 2003. - 279 с.

7. Рудской А. И., Коджаспиров Г. Е. Ультрамелкозернистые металлические материалы. СПб.: Изд-во Политехн. ун-та, 2015. - 360 с.

8. Degtyarev M. V., Chashchukhina T. I., Voronova L. M. Grain Growth in Dynamically Recrystallized Copper During Annealing above and below the Temperature of Thermally Activated Nucleation // Diagnostics, Resource and Mechanics of materials and structures. 2016. - Iss. 5. - P. 15-29. - DOI: 10.17804/2410-9908.2016.5.015-029. - URL: http://dreamjournal.org/DREAM_Issue_5_2016_Degtyarev_M.V._et_al._015_029.pdf.

9. Improvement of wear resistance of hardened structural steel by nanostructuring frictional treatment / A. V. Makarov, N. A. Pozdeeva, R. A. Savrai, A. S. Yurovskikh, I. Yu. Malygina // Journal of Friction and Wear. - 2012. - Vol. 33, no. 6. - P. 433-442. DOI: $10.3103 / \mathrm{S} 10683666120600$.

10. Improving the thermal stability and heat wear resistance of carburized chromium-nickel steel by nanostructuring frictional treatment / A. V. Makarov, N. A. Davydova, I. Y. Malygina, V. V. Lyzhin, L. G. Korshunov // Diagnostics, Resource and Mechanics of materials and structures. 2016. - Iss. 5. - P. 49-66. - DOI: 10.17804/2410-9908.2016.5.049-066. - URL: http://dreamjournal.org/DREAM_Issue_5_2016_Makarov_A.V._et_al._049_066.pdf.

11. Влияние режимов объемного наноструктурирования мегапластической деформацией на свойства конструкционной стали / С. П. Яковлева, С. Н. Махарова, П. Г. Мордовской, М. 3. Борисова // Перспективные материалы. - 2011. - № 13. - С. 961-967.

12. Яковлева С. П., Махарова С. Н., Мордовской П. Г. Влияние комбинированной мегапластической деформации на структуру и свойства стали 09Г2С // Обработка металлов. 2016. - № 1 (70). - C. 52-56.

13. Influence of equal-channel angular pressing on the structure and mechanical properties of low-carbon steel 10G2FT / E. G. Astafurova, G. G. Zakharova, E. V. Naydenkin, S. V. Dobatkin, G. I. Raab // The Physics of Metals and Metallography. - 2010. - Vol. 110, no. 3. - P. 275-284. DOI: $10.1134 / \mathrm{S} 0031918 X 10090097$.

14. Сэстри Ш. М. Л., Добаткин С. В., Сидорова С. В. Формирование субмикрокристаллической структуры в стали 10Г2ФТ при холодном равноканальном угловом прессовании и последующем нагреве // Металлы. - 2004. - № 2. - С. 28-35.

15. Теплое и горячее равноканальное угловое прессование низкоуглеродистых сталей / С. В. Добаткин, П. Д. Одесский, Р. Пиппан, Г. И. Рааб, Н. А. Красильников, А. М. Арсенкин // Металлы. - 2004. - № 1. - С. 110-119.

16. Development of the rotational mode of plastic deformation upon drawing of pearlitic steels of various alloying system / N. A. Tereshchenko, I. L. Yakovleva, M. V. Chukin, Y. Y. Efimova // The Physics of Metals and Metallography. - 2015. - Vol. 116, no. 3. - P. 289-299. DOI: $10.1134 / \mathrm{S} 0031918 X 15030151$.

17. Гаврилюк В. Г. Распределение углерода в стали. - Киев : Наукова думка, 1987. - 208 с.

18. Dobatkin S. V., Kaputkina L. M. Maps of structural states for the optimization of hotworking regimes of steels // The Physics of Metals and Metallography. - 2001. - Vol. 91, no. 1. P. 75-84.

19. Механические свойства феррито-перлитной и мартенситной стали $10 Г 2 Ф Т$ после равноканального углового прессования и высокотемпературных отжигов / Г. Г. Захарова, Е. Г. Астафурова, М. С. Тукеева, Е. В. Найденкин, Г. И. Рааб, С. В. Добаткин // Известия высших учебных заведений. Физика. - 2011. - № 4. - С. 23-28. 